\title{
Revealing the Correlation between Catalytic Selectivity and the Local Coordination Environment of Pt Single Atom
}

\author{
Yong Xu, ${ }^{1,2, \dagger}$ Mingyu Chu, ${ }^{2, \dagger}$ Fangfang Liu, ${ }^{2, \dagger}$ Xuchun Wang, ${ }^{2, \dagger}$ Yu Liu, ${ }^{2}$ Muhan Cao, ${ }^{2}$ Jing Gong, ${ }^{2}$ Jun \\ Luo, ${ }^{3}$ Haiping Lin $2,{ }^{*}$ Youyong Li, ${ }^{2}$ Qiao Zhang $2, *$
}

${ }^{1}$ Guangzhou Key Laboratory of Low-Dimensional Materials and Energy Storage Devices, Collaborative Innovation Center of Advanced Energy Materials, School of Materials and Energy, Guangdong University of Technology, Guangzhou, 510006, Guangdong, China

${ }^{2}$ Institute of Functional Nano \& Soft Materials (FUNSOM), Jiangsu Key Laboratory for Carbon-Based Functional Materials and Devices, Soochow University, Jiangsu, 215123, China

${ }^{3}$ Institute for New Energy Materials and Low-Carbon Technologies, School of Materials Science and Engineering, Tianjin University of Technology, Tianjin, 300384, China

*E-mail: hplin@suda.edu.cn

*E-mail: qiaozhang@suda.edu.cn 


\section{EXPERIMENTAL SECTION}

Synthesis of $\mathbf{F e O O H . ~ F e O O H ~ n a n o s t r u c t u r e s ~ w e r e ~ p r e p a r e d ~ v i a ~ a ~ s i m p l e ~ h y d r o t h e r m a l ~ p r o c e s s ~ b y ~}$ adding $\mathrm{FeSO}_{4} \cdot 7 \mathrm{H}_{2} \mathrm{O}$, glycerol and deionized water into a Teflon-lined stainless autoclave. ${ }^{1}$ In a typical synthesis process, $0.111 \mathrm{~g}$ of $\mathrm{FeSO}_{4} \cdot 7 \mathrm{H}_{2} \mathrm{O}$ was dissolved in $37 \mathrm{~mL}$ deionized water and subsequently mixed with $3 \mathrm{~mL}$ glycerol under stirring at room temperature for $15 \mathrm{~min}$. Afterward, the mixed solution was transferred into a $100 \mathrm{~mL}$ Teflon-lined stainless-steel autoclave and heated to $120{ }^{\circ} \mathrm{C}$ for $24 \mathrm{~h}$. After cooling to room temperature, the sediments were washed by water and then by ethanol for 3 times, respectively, followed by drying in oven at $80{ }^{\circ} \mathrm{C}$ overnight.

Preparation of $\mathbf{P t} / \mathbf{F e O}_{\mathbf{x}} \mathrm{H}_{\mathbf{y}}$ SACs and $\mathbf{F e O}_{x} \mathbf{H}_{y}$-supported Pt nanoparticles. $\mathrm{Pt} / \mathrm{FeO}_{\mathrm{x}} \mathrm{H}_{\mathrm{y}}$ SACs were prepared by depositing a certain amount of $\operatorname{Pt}\left(\mathrm{NH}_{3}\right)\left(\mathrm{NO}_{3}\right)_{2}$ on FeOOH. Afterward, the samples were dried at $100{ }^{\circ} \mathrm{C}$ for $24 \mathrm{~h}$ in an oven and then calcinated at different temperatures for $2 \mathrm{~h}$, which were termed as S-1 $\left(160{ }^{\circ} \mathrm{C}\right)$, S-2 $\left(200{ }^{\circ} \mathrm{C}\right)$, S-3 $\left(300^{\circ} \mathrm{C}\right)$, and S-4 $\left(400{ }^{\circ} \mathrm{C}\right)$, respectively. We took S-4 as an example, $2 \mathrm{mg}$ of $\mathrm{Pt}\left(\mathrm{NH}_{3}\right)\left(\mathrm{NO}_{3}\right)_{2}$ was dissolved in $1 \mathrm{~mL}$ deionized water, which was dropwise added onto $1 \mathrm{~g}$ FeOOH powder in a $20 \mathrm{~mL}$ bottle. The bottle was put on a hotplate with $80{ }^{\circ} \mathrm{C}$ under magnetic stirring until a slurry was obtained. Afterward, the slurry was aged at the same temperature without disturbed for $1 \mathrm{~h}$ and then dried in an oven at $100{ }^{\circ} \mathrm{C}$ for $24 \mathrm{~h}$. $\mathrm{FeO}_{\mathrm{x}} \mathrm{H}_{\mathrm{y}}$-supported Pt nanoparticles (e.g., $0.5 \% \mathrm{Pt}-\mathrm{FeO}_{\mathrm{x}} \mathrm{H}_{\mathrm{y}}$ and $1 \% \mathrm{Pt}-\mathrm{FeO}_{\mathrm{x}} \mathrm{H}_{\mathrm{y}}$ ) were prepared via a wet impregnation method. A certain amount of $\mathrm{Pt}\left(\mathrm{NH}_{3}\right)\left(\mathrm{NO}_{3}\right)_{2}$ solution was added into FeOOH powder to form a slurry, followed by an ultrasonic treatment for $30 \mathrm{~min}$. Afterward, the slurry was dried at $100{ }^{\circ} \mathrm{C}$ for $24 \mathrm{~h}$ and then calcinated at $400{ }^{\circ} \mathrm{C}$ for $2 \mathrm{~h}$. Prior to catalytic test, $0.5 \% \mathrm{Pt}-\mathrm{FeO}_{\mathrm{x}} \mathrm{H}_{\mathrm{y}}$ and $1 \% \mathrm{Pt}-\mathrm{FeO}_{\mathrm{x}} \mathrm{H}_{\mathrm{y}}$ were reduced by $\mathrm{H}_{2}$ at $160{ }^{\circ} \mathrm{C}$ for $2 \mathrm{~h}$.

Characterization. Transmission electron microscopy (TEM) measurement was performed on a TECNAI G2 LaB6 operated at $200 \mathrm{kV}$. Scanning electron microscopy (SEM) images were taken at 5 kV by using the Supra 55 SEM from Carl Zeiss, Germany. Aberration-corrected STEM images with a 
probe corrector were obtained on Titan Cubed Themis G2 300 at 200 kV. The loading amounts of Pt in $\mathrm{Pt} / \mathrm{FeO}_{\mathrm{x}} \mathrm{H}_{\mathrm{y}} \mathrm{SACs}$ were determined by the inductively coupled plasma atomic emission spectroscopy (ICP-AES) (710-ES, Varian). XRD patterns were collected on X'Pert-Pro MPD diffractometer (Netherlands PANalytical) with a $\mathrm{Cu} \mathrm{K \alpha} \mathrm{X-ray} \mathrm{source}(\lambda=1.540598 \AA)$. X-ray photoelectron spectroscopy measurement was performed on a Kratos AXIS Untraded ultrahigh vacuum (UHV) surface analysis system, and the binding energy of C $1 \mathrm{~s}(285.6 \mathrm{eV})$ was used as the reference. The Xray absorption data at the Pt $L$-edge were collected at 20ID beamline of the Advanced Photon Source (APS) operated by Argonne National Laboratory, USA. The extended X-ray absorption fine structure (EXAFS) data were fitted in $R$ space using Artemis. The fitted $\mathrm{k}$ range (Hanning window with $\mathrm{d} k=1$ ) were set to be $3.0-10.5 \AA^{-1}$ for Pt $L_{3}$-edge. The fitted $R$ ranges (Hanning window with $\mathrm{d} R=0.5$ ) were set to be 1.1-2.5 $\AA$ for Pt $L_{3}$-edge. Wavelet transform Morlet wavelet was used to conduct wavelet transform of EXAFS spectra at Pt $L_{3}$-edge with the following mathematical equation:

$$
\psi(t)=\frac{1}{\sqrt{2 \pi} \sigma}\left(\exp (i \kappa t)-\exp \left(-\frac{\kappa^{2}}{2}\right)\right) \exp \left(-\frac{t^{2}}{2 \sigma^{2}}\right)
$$

Where $\kappa$ is the frequency of sine and cosine functions, indicating how much oscillations of the sine wave are contained by a Gaussian envelope with a half-width $\sigma$. In this work, $\kappa$ and $\sigma$ were set at 15 and 1, respectively. The $k$ and $R$ space were set at 3.0 to $10.5 \AA^{-1}$ and 0 to $6 \AA$, respectively. A $k^{3}$ weighting was used in this case. The diffuse reflectance infrared Fourier transform spectroscopy (DRIFTS) measurement was performed on a commercial system equipped a Thermo Scientific Nicolet 6700 Fourier transform infrared spectrometer and liquid nitrogen cooled mercury-cadmium-telluride detector (MCT) using $\mathrm{CO}$ as the prober molecules. Typically, $40 \mathrm{mg}$ of sample was put into a cell, which was pre-treated by heating in $\mathrm{CO} / \mathrm{Ar}(10 \mathrm{vol} . \%)$ flow $(50 \mathrm{~mL} / \mathrm{min})$ at $0{ }^{\circ} \mathrm{C}$ for $30 \mathrm{~min}$, followed by flushing with Ar flow (50 mL/min) for another $30 \mathrm{~min}$. In-situ DRIFTS test was performed by introducing $\mathrm{C}_{3} \mathrm{H}_{4} / \mathrm{H}_{2}$ (volume ratio: 1/10) into the cell with the same pre-treatment. The CO-DRIFTS spectra were obtained by averaging 16 sequentially collected scans at a resolution of $4 \mathrm{~cm}^{-1}$. 
Catalytic test. All the catalysts were evaluated in a fixed quartz reactor with an inner diameter of 10 mm. $100 \mathrm{mg}$ catalyst was fixed in the reactor. The flow rates of $\mathrm{C}_{3} \mathrm{H}_{4}, \mathrm{H}_{2}$ and $\mathrm{N}_{2}$ were controlled by three independent mass flow controllers. The hydrocarbons were detected by a gas chromatographs (GC) equipped with a flame ionization detector (FID) using a capillary-column (Model: $\mathrm{TM}-\mathrm{Al}_{2} \mathrm{O}_{3} / \mathrm{S}$, $30 \mathrm{~m})$. The temperatures of column, vaporizing chamber, and detector for FID were 70, 200, and 200 ${ }^{\circ} \mathrm{C}$, respectively. $\mathrm{H}_{2}$ and $\mathrm{N}_{2}$ were detected by another GC equipped with a thermal conductivity detector using a packed column (Model: TDX-01, $3 \mathrm{~m}$ ). The temperatures of column, vaporizing chamber, and detector for TCD were 60,130 , and $120^{\circ} \mathrm{C}$, respectively, and the current of TCD was $45 \mathrm{~mA}$. The PSH conditions were $T=120{ }^{\circ} \mathrm{C}, P_{\text {total }}=0.1 \mathrm{MPa}$, and $\mathrm{C}_{3} \mathrm{H}_{4} / \mathrm{H}_{2} / \mathrm{N}_{2}=3 / 30 / 2 \mathrm{~mL} / \mathrm{min}$. TOF value, selectivity, and space time yield (STY) were employed to evaluate the performance of PSH, which were calculated by the equations $2-5$.

$$
\begin{aligned}
& \text { TOF }=\frac{n\left(\mathrm{C}_{3} \mathrm{H}_{4}\right)_{\text {in }}-n\left(\mathrm{C}_{3} \mathrm{H}_{4}\right)_{\text {out }}}{n(\mathrm{Pt}) \times t} \quad \text { (2) } \\
& \mathrm{C}_{3} \mathrm{H}_{6} \text { Sel. }(\%)=\frac{n\left(\mathrm{C}_{3} \mathrm{H}_{6}\right)_{\text {out }}}{n\left(\mathrm{C}_{3} \mathrm{H}_{4}\right)_{\text {in }}-n\left(\mathrm{C}_{3} \mathrm{H}_{4}\right)_{\text {out }}} \times 100 \% \\
& \mathrm{C}_{3} \mathrm{H}_{8} \text { Sel. }(\%)=\frac{n\left(\mathrm{C}_{3} \mathrm{H}_{8}\right)_{\text {out }}}{n\left(\mathrm{C}_{3} \mathrm{H}_{4}\right)_{\text {in }}-n\left(\mathrm{C}_{3} \mathrm{H}_{4}\right)_{\text {out }}} \times 100 \% \\
& \mathrm{C}_{3} \mathrm{H}_{6} \text { STY }=\frac{n\left(\mathrm{C}_{3} \mathrm{H}_{6}\right)_{\text {out }}}{n(\mathrm{Pt}) \times t} \quad \text { (5) }
\end{aligned}
$$

Density functional theory (DFT) calculations. Spin-polarized DFT calculations were carried out with the Vienna Ab initio Simulation Package (VASP). ${ }^{2}$ The ion-electron interactions were described by the projector augmented wave (PAW) potentials. ${ }^{3}$ The Perdew-Burke-Ernzerhof (PBE) functional within a generalized gradient approximation (GGA) was employed to describe the exchange-correlation interactions.4 The cutoff energy of plane wave basis was set as $500 \mathrm{eV}$. The surfaces of $\alpha$-phase $\mathrm{Fe}_{2} \mathrm{O}_{3}(001) 5$ and $\alpha$-phase (Pbnm) FeOOH$(110)^{6}$ were mimicked with slab models consisting of 9 and 
12 atomic layers, respectively. The bottom 5 layers of $\mathrm{Fe}_{2} \mathrm{O}_{3}$ and 6 layers of $\mathrm{FeOOH}$ were kept fixed during structural optimizations. A vacuum space of $15 \AA$ in the out-of-plane direction was added to avoid spurious interactions between the periodic images. The Brillouin zones were sampled by Monkhorst-Pack k-point meshes with separation of $0.02 \AA^{-1}$. The convergence criteria for the residual force and energy during structure relaxation were set to $0.02 \mathrm{eV} / \AA$ and $1 \times 10^{-4} \mathrm{eV}$, respectively. The van der Waals dispersion correction was applied using the DFT-D3 method. ${ }^{7}$ The climbing image-nudged elastic band (CI-NEB) and the Dimer method were used to search transition states and minimum energy paths. ${ }^{8-10}$ The adsorption energies $\left(E_{a}\right)$ were calculated by:

$E_{\text {ad }}=E_{\text {adsorbed }}-E_{\text {surface }}-E_{\text {adsorbate }}$ 

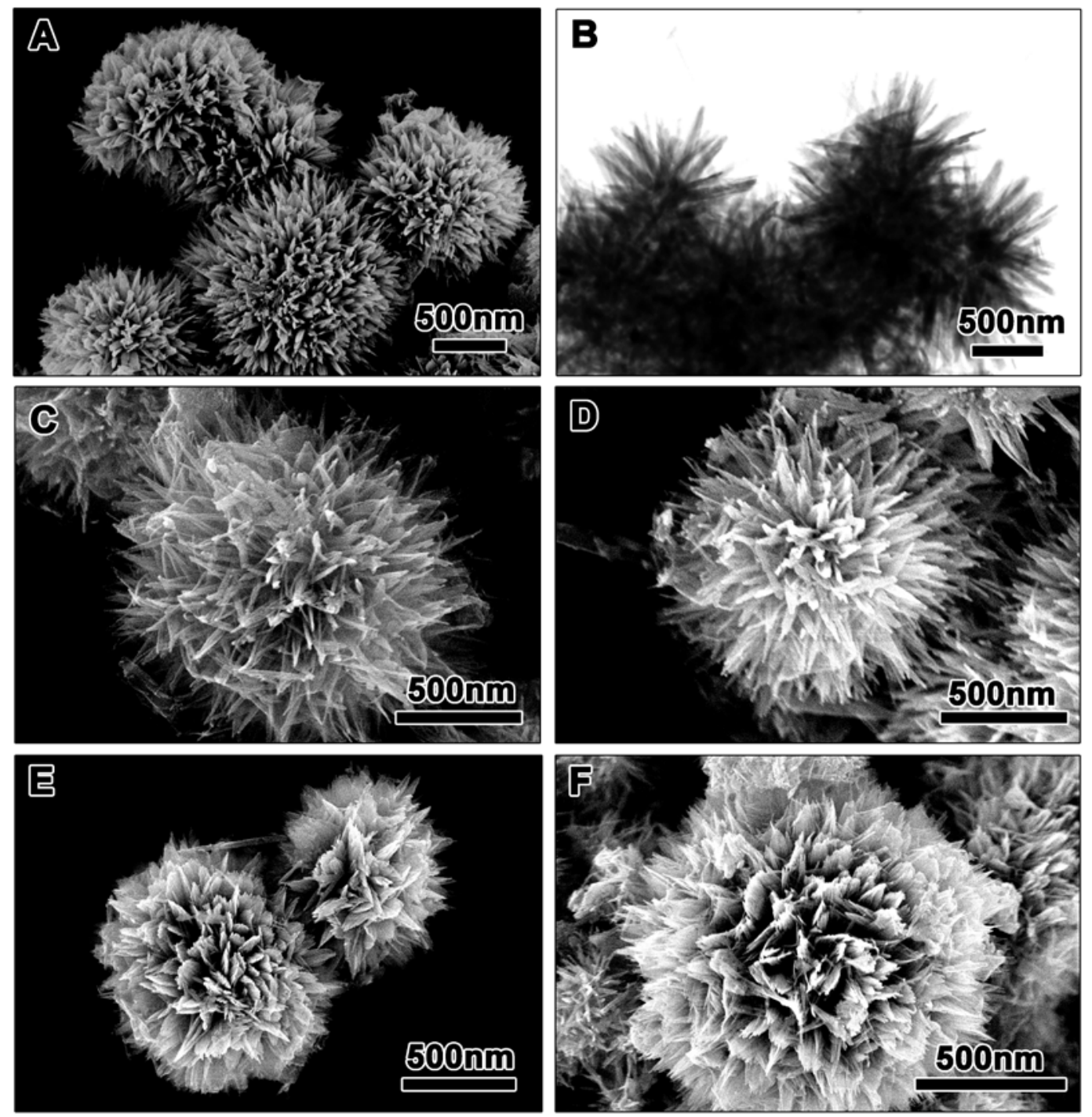

Figure S1. Morphologies of FeOOH and Pt/FeO $\mathbf{H}_{\mathbf{y}}$ SACs. (A) SEM image and (B) TEM image of the as-prepared FeOOH. (C) SEM image of S-1 catalyst. (D) SEM image of S-2 catalyst. (E) SEM image of S-3 catalyst. (F) SEM image of S-4 catalyst. 


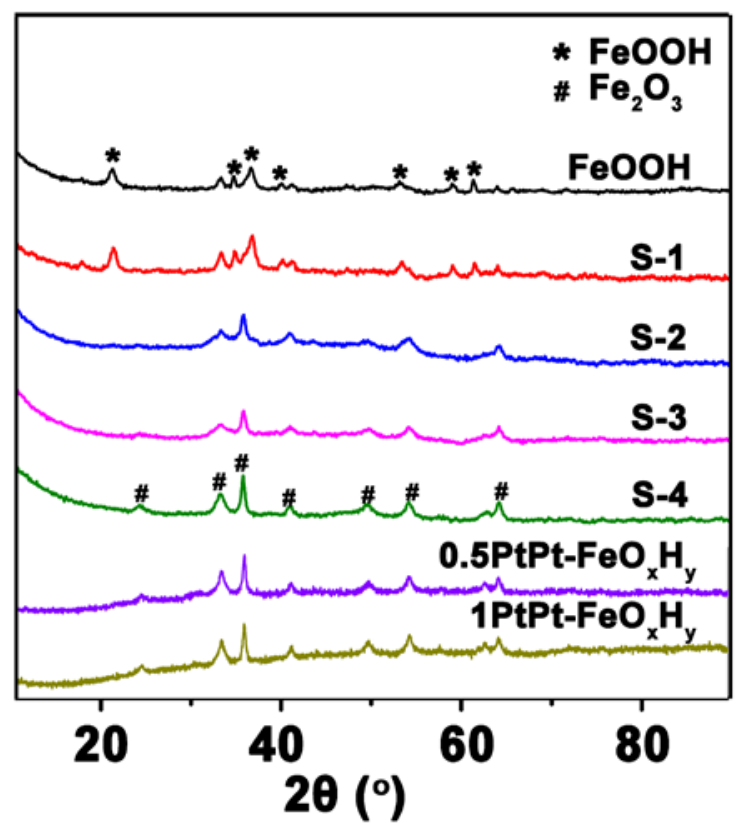

Figure S2. XRD patterns of FeOOH and catalysts. 

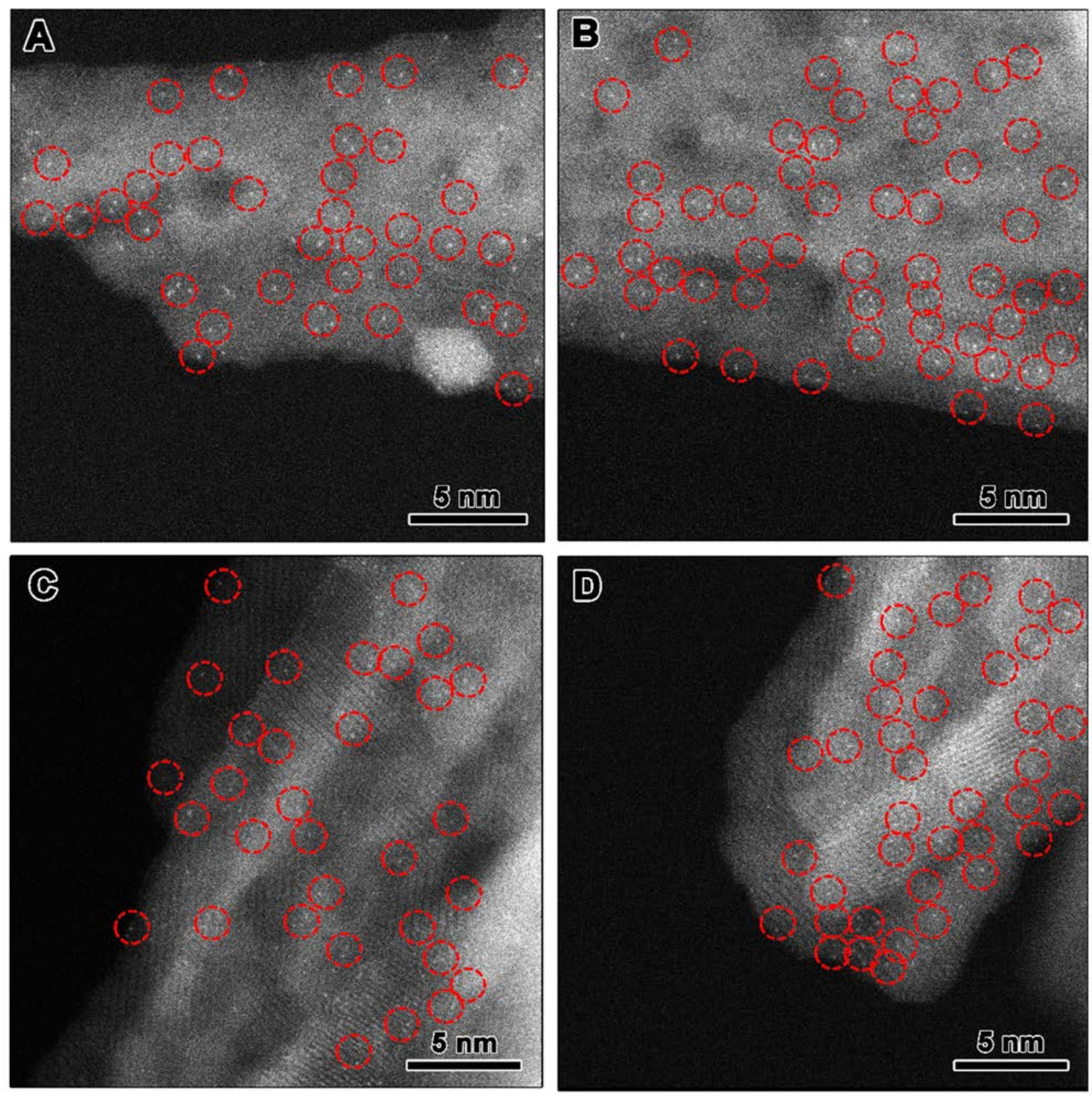

Figure S3. (A-D) AC-STEM images of Pt/FeO $\mathbf{H}_{\mathbf{y}}$ SACs (S-4) at different positions. Pt single atoms are labeled by red dash cycles in the AC-STEM images. 


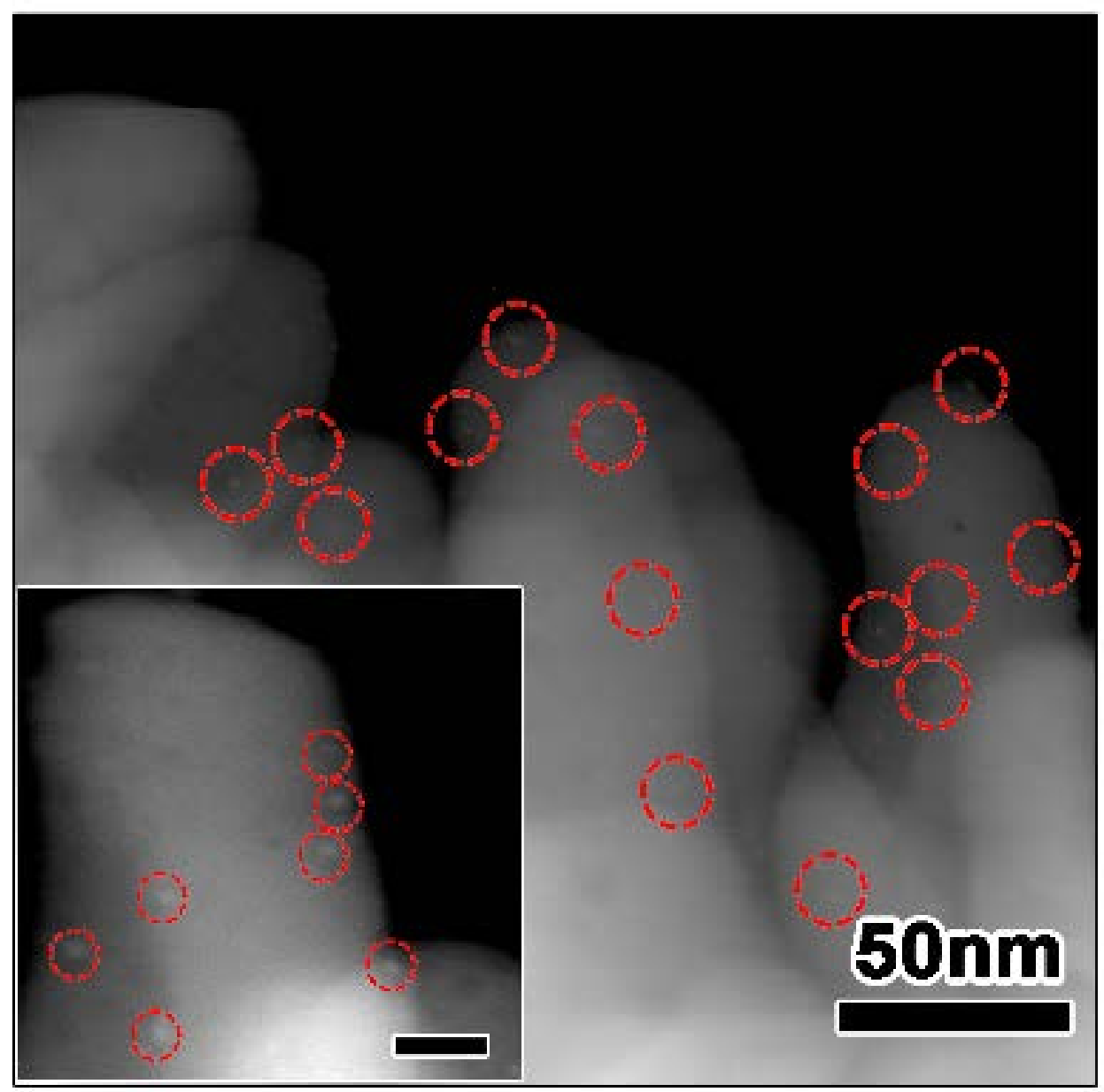

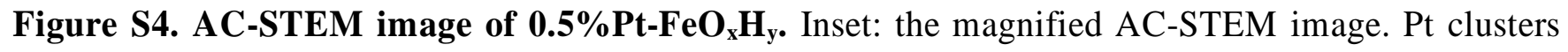
are labeled by red dash cycles in the AC-STEM images. The scale bar of the inset is $5 \mathrm{~nm}$. 


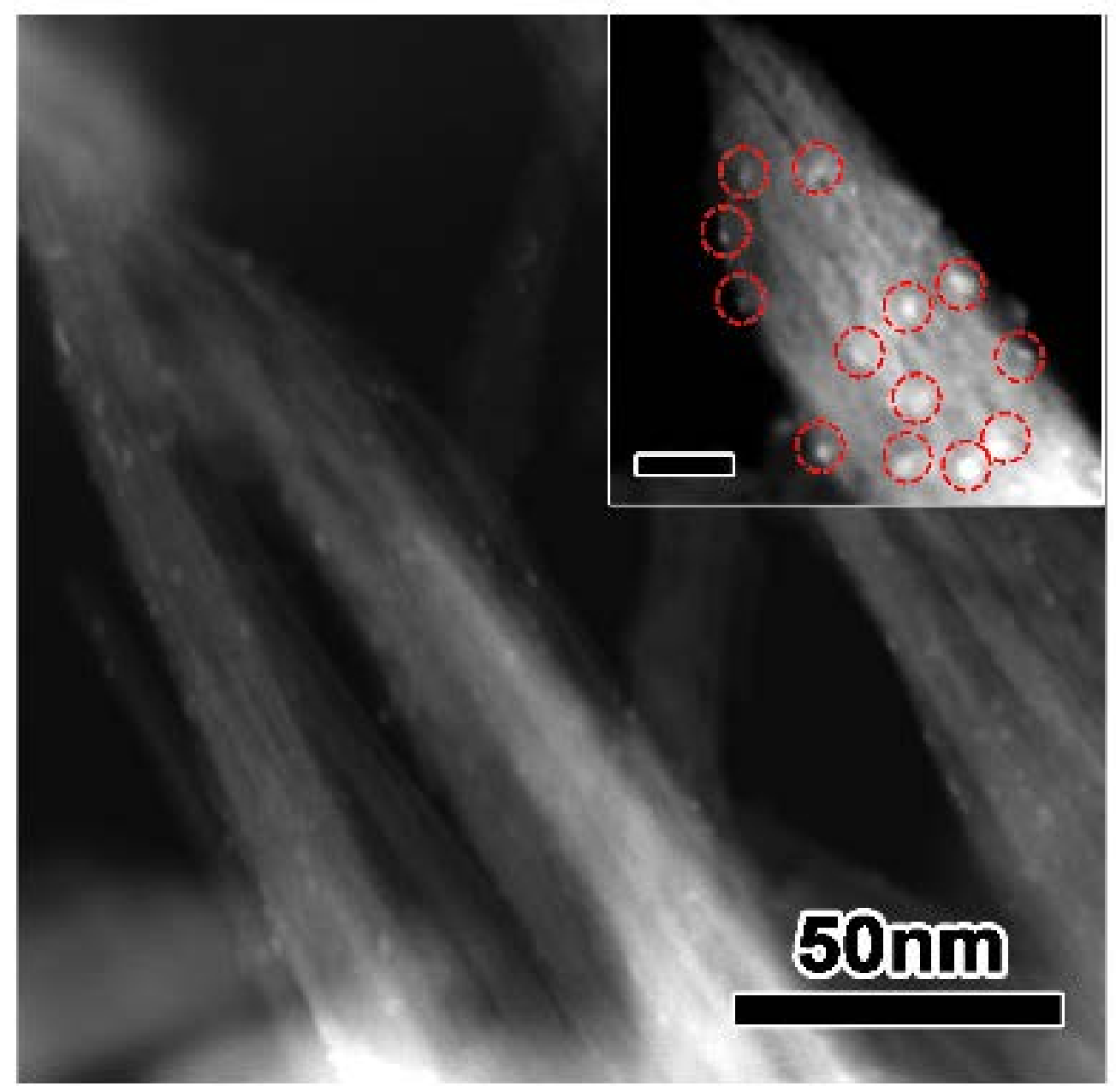

Figure S5. AC-STEM image of $\mathbf{1} \% \mathrm{Pt}-\mathrm{FeO}_{\mathrm{x}} \mathrm{H}_{\mathbf{y}}$. Inset: the magnified AC-STEM image. Pt clusters are labeled by red dash cycles in the AC-STEM images. The scale bar of the inset is $5 \mathrm{~nm}$. 

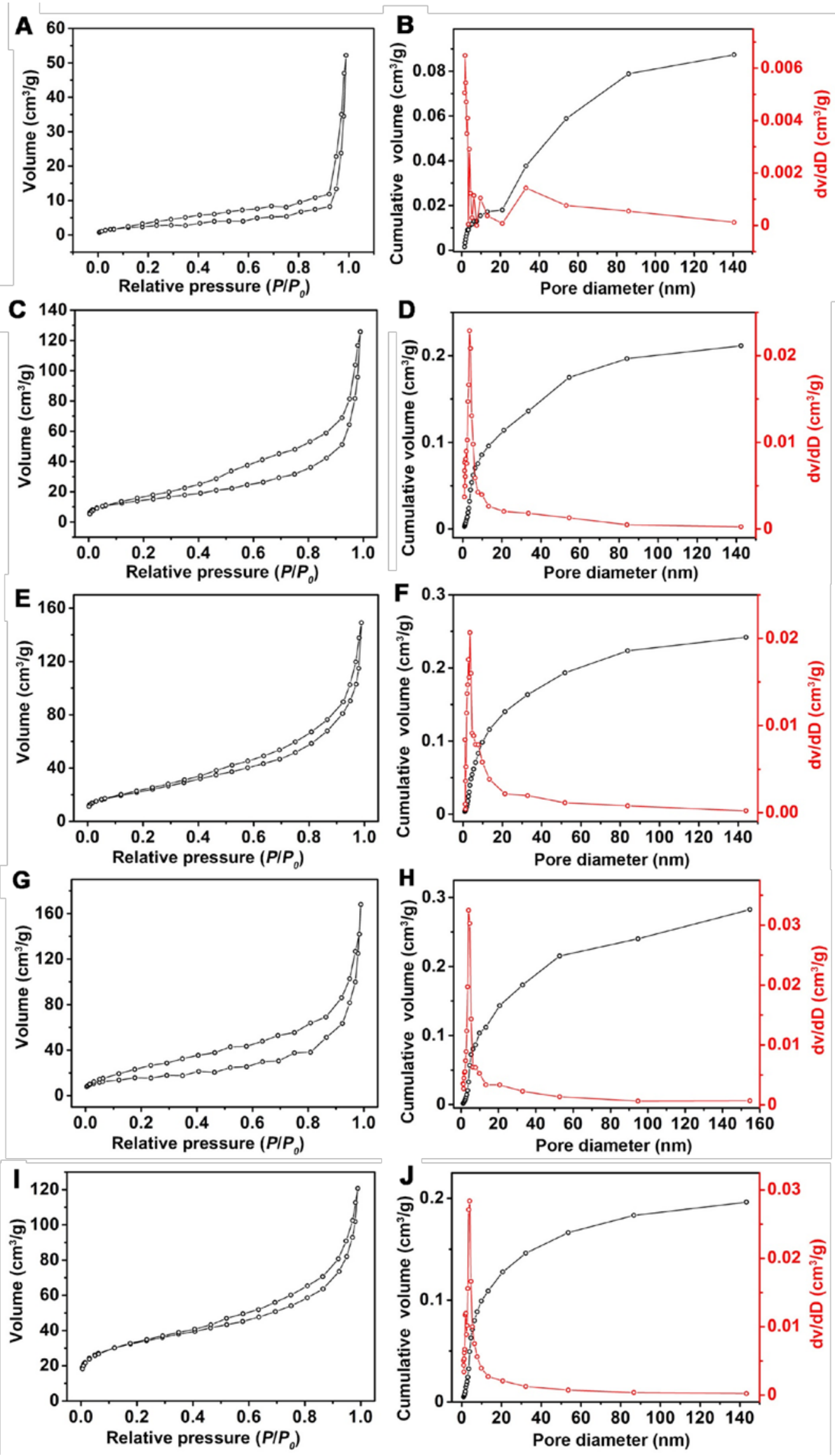
Figure S6. $\mathrm{N}_{2}$ adsorption-desorption isotherms and corresponding pore size distribution curves. $\mathrm{N}_{2}$ adsorption-desorption isotherms of FeOOH (A), S-1 (C), S-2 (E), S-3 (G), and S-4 (I). Pore size distribution curves of FeOOH (B), S-1 (D), S-2 (F), S-3 (H), and S-4 (J). Note that all SACs exhibit type IV isotherms with a hysteresis loop, thereby suggesting the presence of mesopores. ${ }^{11,12}$

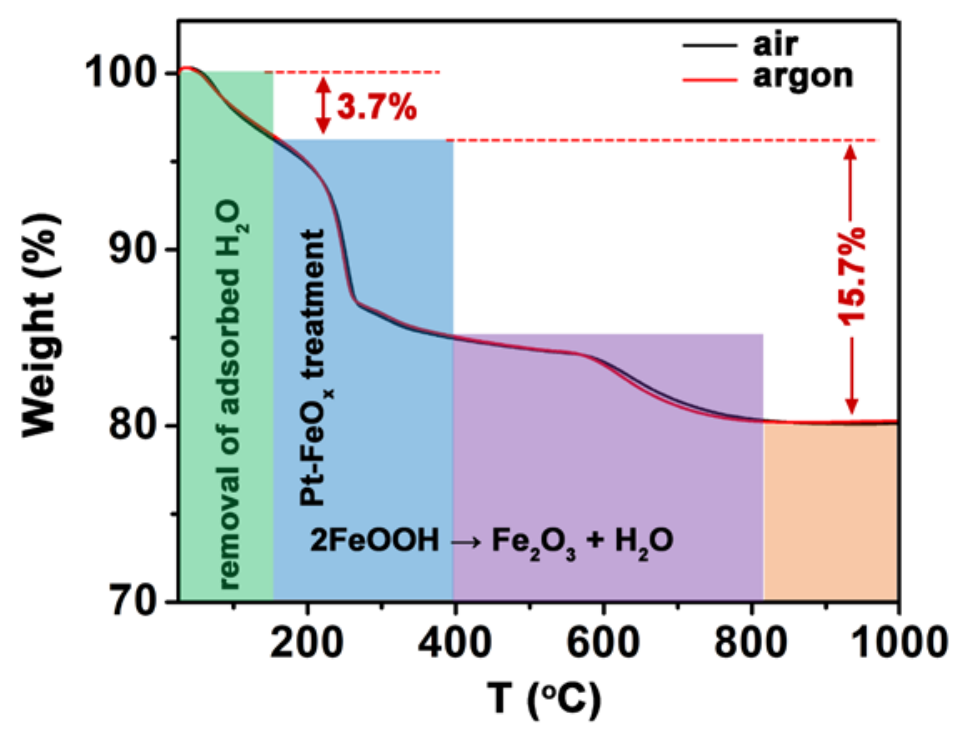

Figure S7. TGA curve of $\mathrm{FeOOH}$ in the temperature range of $30-1000{ }^{\circ} \mathrm{C}$. TGA measurement was performed in both $\mathrm{Ar}$ and air with a heating rate of $10^{\circ} \mathrm{C} / \mathrm{min}$. 

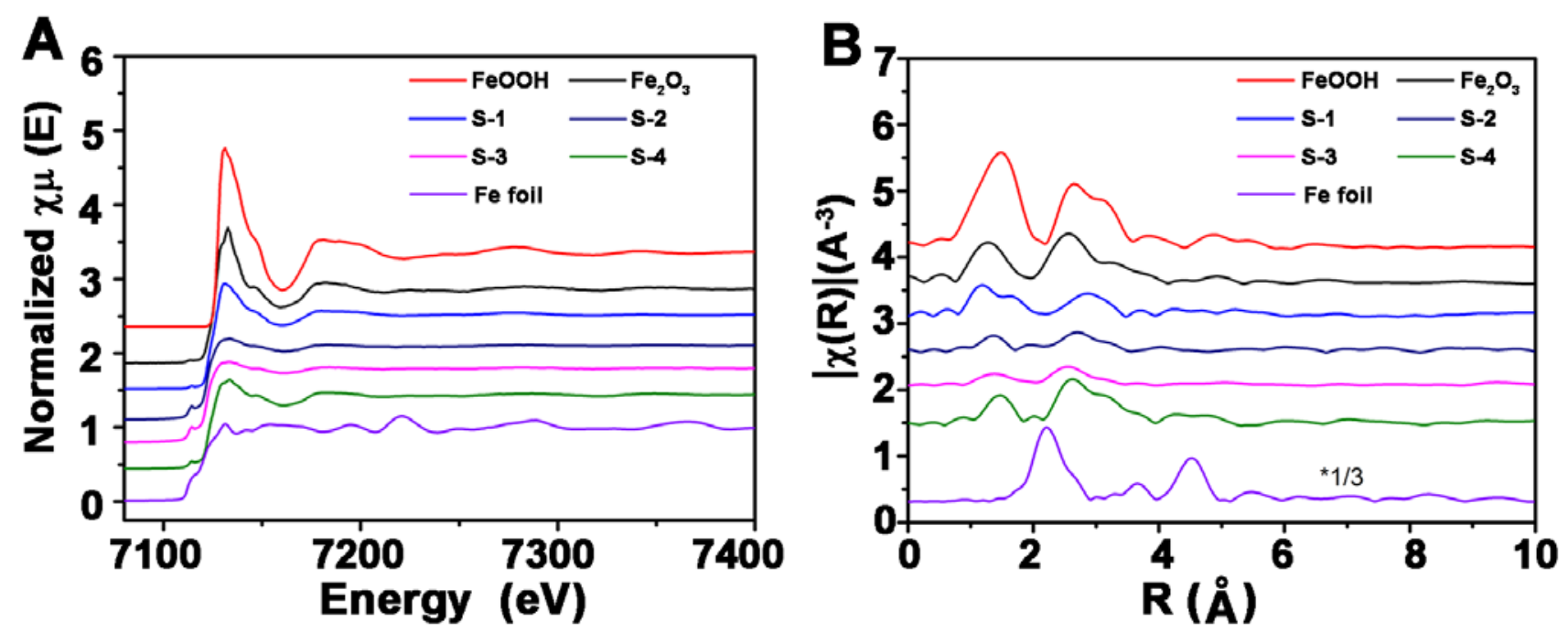

Figure S8. Structural analysis of $\mathbf{P t} / \mathbf{F e O}_{\mathbf{x}} \mathbf{H}_{\mathbf{y}}$ SACs. (A) XANES spectra of $\mathrm{Pt} / \mathrm{FeO}_{\mathrm{x}} \mathrm{H}_{\mathrm{y}} \mathrm{SACs}$, Fe foil and $\mathrm{Fe}_{2} \mathrm{O}_{3}$ at Fe K-edge. (B) EXAFS spectra of $\mathrm{Pt} / \mathrm{FeO}_{\mathrm{x}} \mathrm{H}_{\mathrm{y}} \mathrm{SACs}$, Fe foil and $\mathrm{Fe}_{2} \mathrm{O}_{3}$ at $\mathrm{Fe} \mathrm{K}$-edge. 

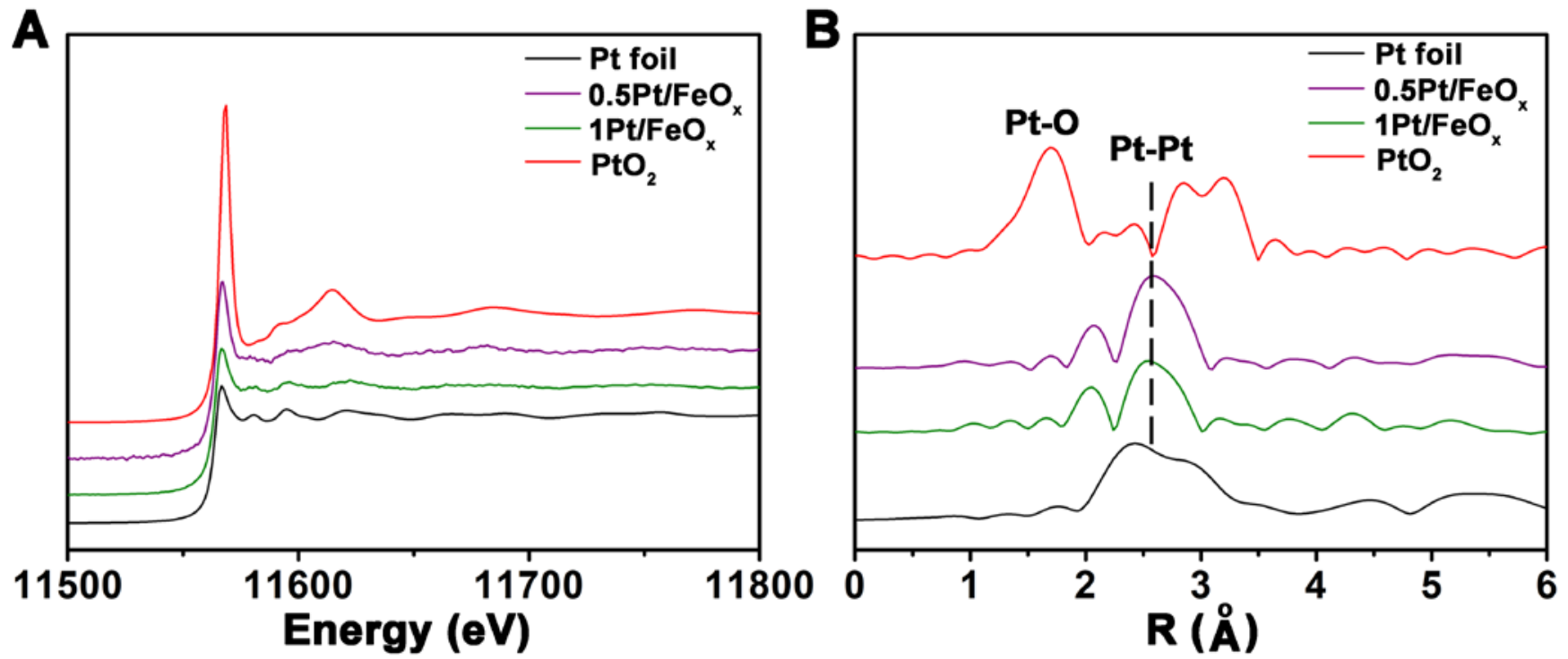

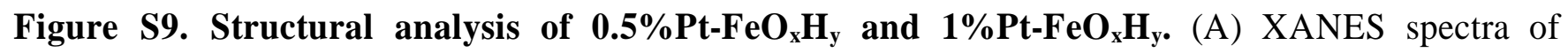
0.5\%Pt-FeO $\mathrm{H}_{y}, 1 \% \mathrm{Pt}-\mathrm{FeO}_{\mathrm{x}} \mathrm{H}_{\mathrm{y}}$, Pt foil and $\mathrm{PtO}_{2}$ at Pt $\mathrm{L}_{3}$-edge. (B) EXAFS spectra of $0.5 \% \mathrm{Pt}-\mathrm{FeO}_{\mathrm{x}} \mathrm{H}_{\mathrm{y}}$, 1\%Pt-FeO $\mathrm{H}_{y}, \mathrm{Pt}$ foil and $\mathrm{PtO}_{2}$ at $\mathrm{Pt} L_{3}$-edge. Compared to the references of $\mathrm{Pt}$ foil and $\mathrm{PtO}_{2}$, $\mathrm{Pt}$ in $0.5 \% \mathrm{Pt}-\mathrm{FeO}_{\mathrm{x}}$ and $1 \% \mathrm{Pt}-\mathrm{FeO}_{\mathrm{x}}$ have been partially oxidized. 


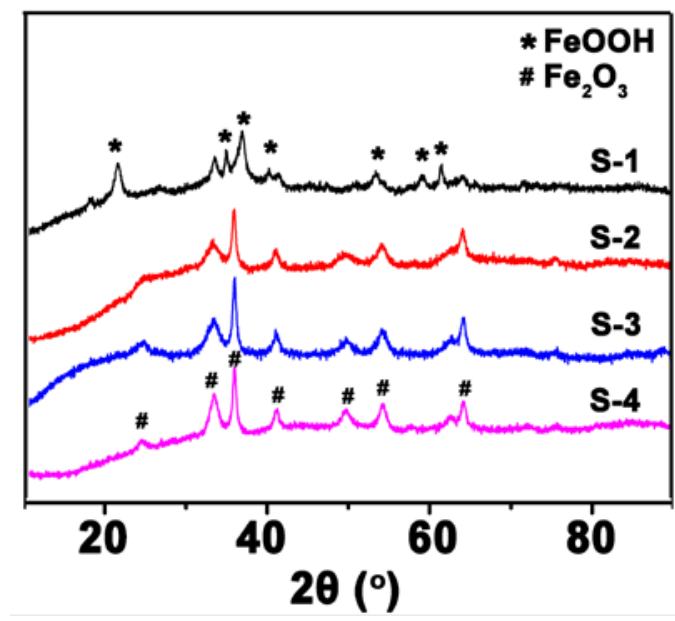

Figure S10. XRD patterns of the spent SACs. 

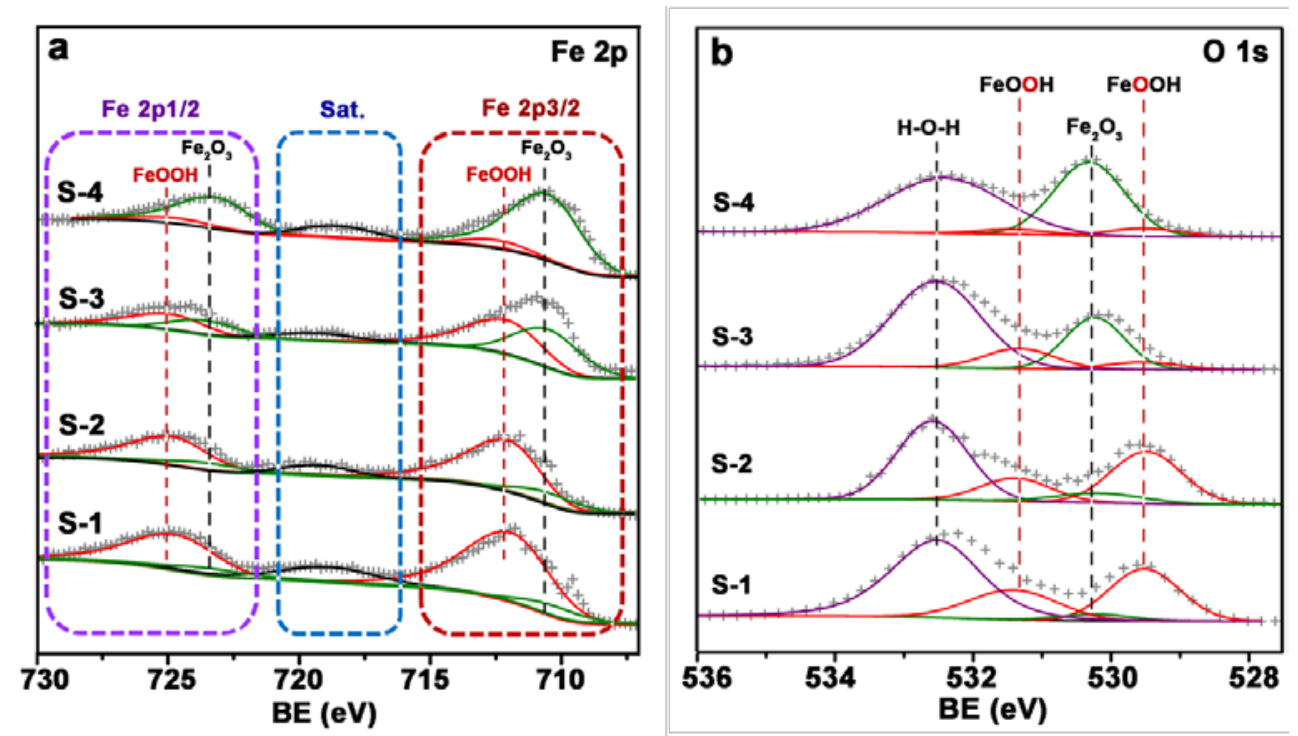

Figure S11. (a) Fe 2p XPS and (b) O 1s spectra of the spent SACs. 
A

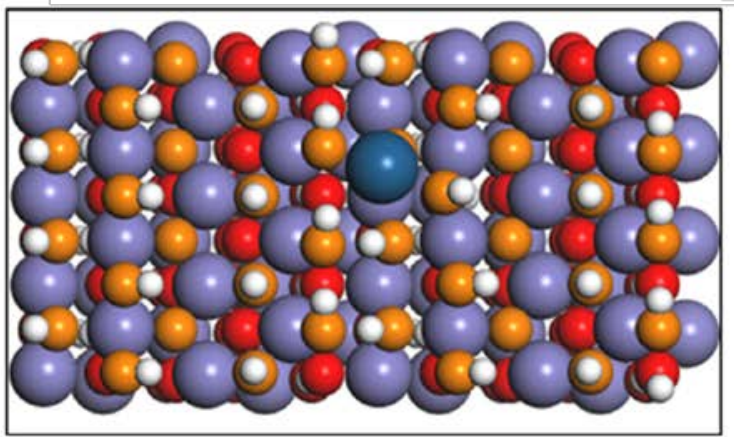

B

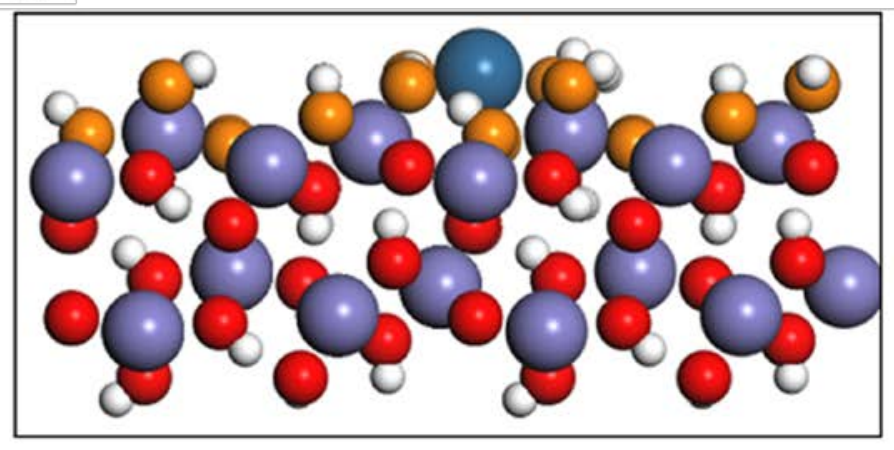

Figure S12. Structure of Pt single atom on FeOOH (110) surface. (A) The top and (B) side views of 3-coordinated Pt single atom on the FeOOH (110), in which the Pt atom replace one of the surface $\mathrm{H}$ atoms and thus bind with two surface $\mathrm{O}$ atoms and one $\mathrm{O}$ atom in the sublayer. Considering the catalyst was exposed to $\mathrm{H}_{2}$ during reaction, $\mathrm{H}$ atoms may adsorb on FeOOH (110) surface. The top two layers of $\mathrm{O}$ atoms, other $\mathrm{O}$ atoms, Fe atoms, Pt atoms and $\mathrm{H}$ atoms are represented by orange, red, purple, blue and white circles, respectively. 

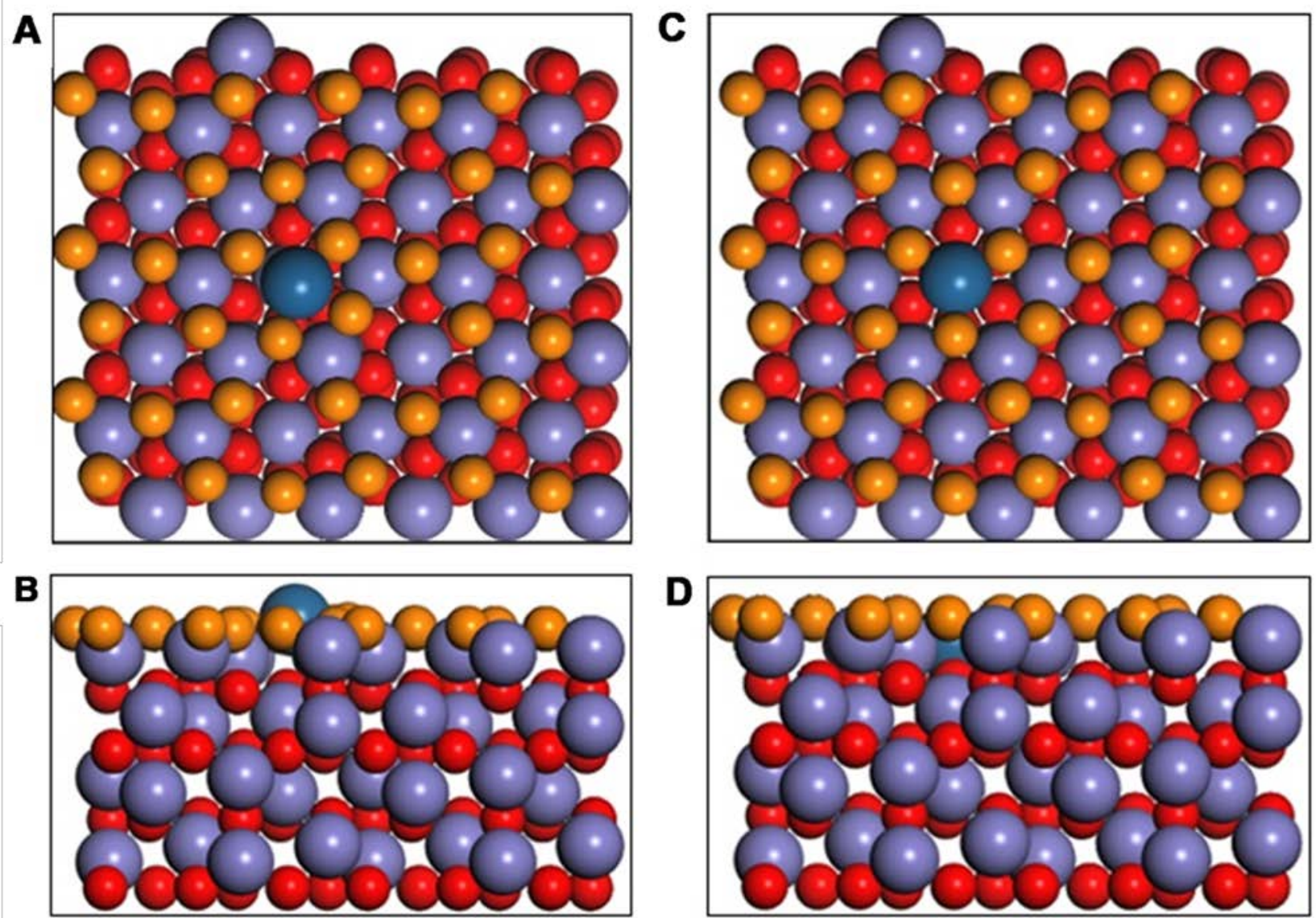

Figure S13. Structure of Pt single atom on $\mathrm{Fe}_{2} \mathrm{O}_{3}(001)$ surface. (A) The top and (B) side views of a 4-coordinated Pt on $\mathrm{Fe}_{2} \mathrm{O}_{3}(001)$ surface, (C) The top and (D) side views of a 7-coordinated Pt on $\mathrm{Fe}_{2} \mathrm{O}_{3}$ (001) surface. The 4-coordinated Pt is $0.42 \mathrm{eV}$ more stable than the 7-coordinated ones. The surface $\mathrm{O}$ atoms, bulk $\mathrm{O}$ atoms, Fe atoms and Pt atoms are represented by orange, red, purple and blue circles, respectively 

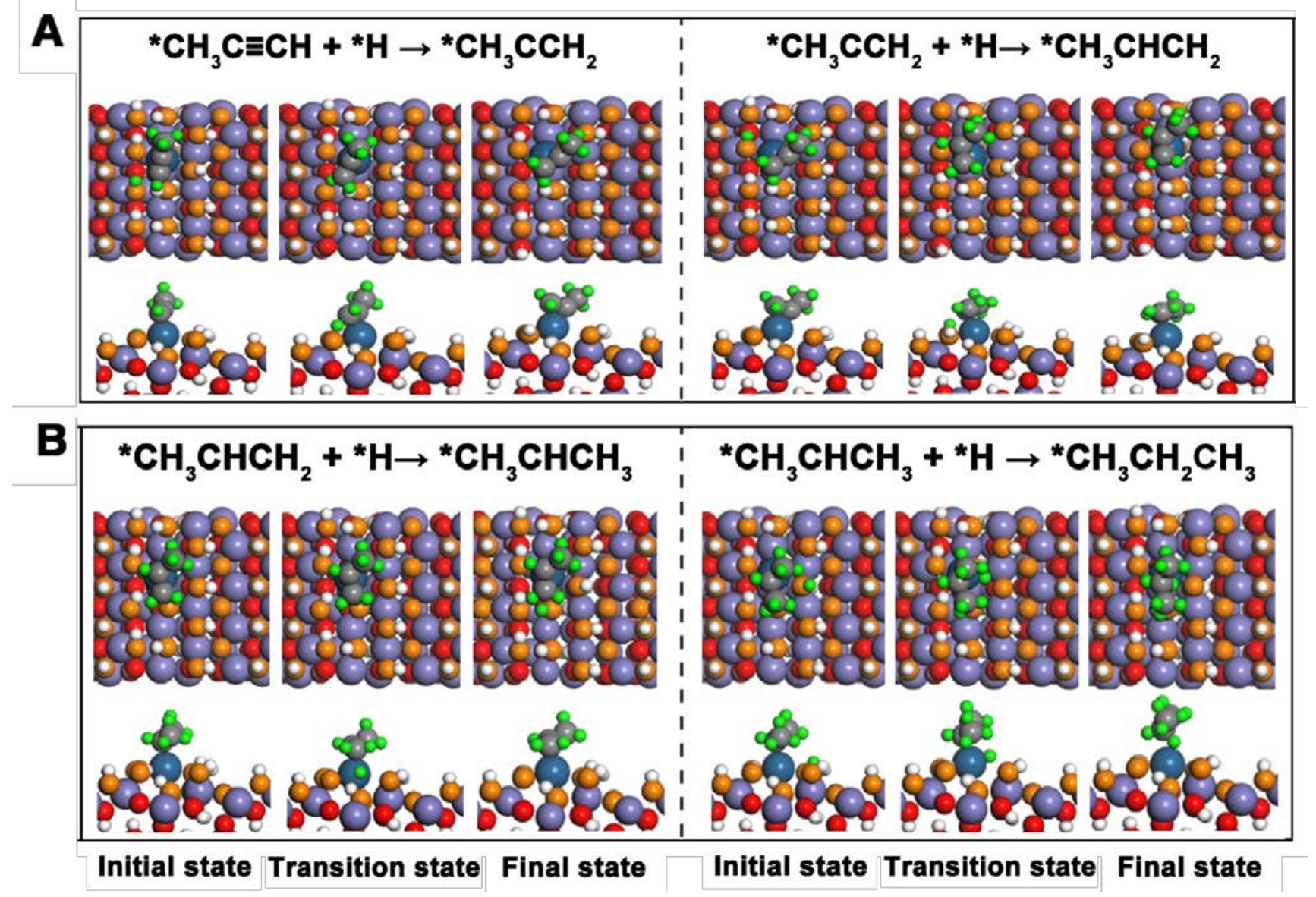

Figure S14. The corresponding atomic structures of different states in $\mathrm{C}-1$ path on $\mathrm{Pt} / \mathrm{FeOOH}$ (110) surface. (A) Top view (top) and side view (bottom) of different states during propyne hydrogenation to propylene, (B) Top view (top) and side view (bottom) of different states during propylene hydrogenation to propane. Considering the catalyst was exposed to $\mathrm{H}_{2}$ during reaction, $\mathrm{H}$ atoms may adsorb on $\mathrm{FeOOH}(110)$ surface. The two $\mathrm{O}$ atoms at top layer, other $\mathrm{O}$ atoms, Fe atoms, $\mathrm{Pt}$ atoms, $\mathrm{H}$ atoms in molecules and other surface $\mathrm{H}$ atoms are represented with orange, red, purple, blue, green and white circles, respectively. 

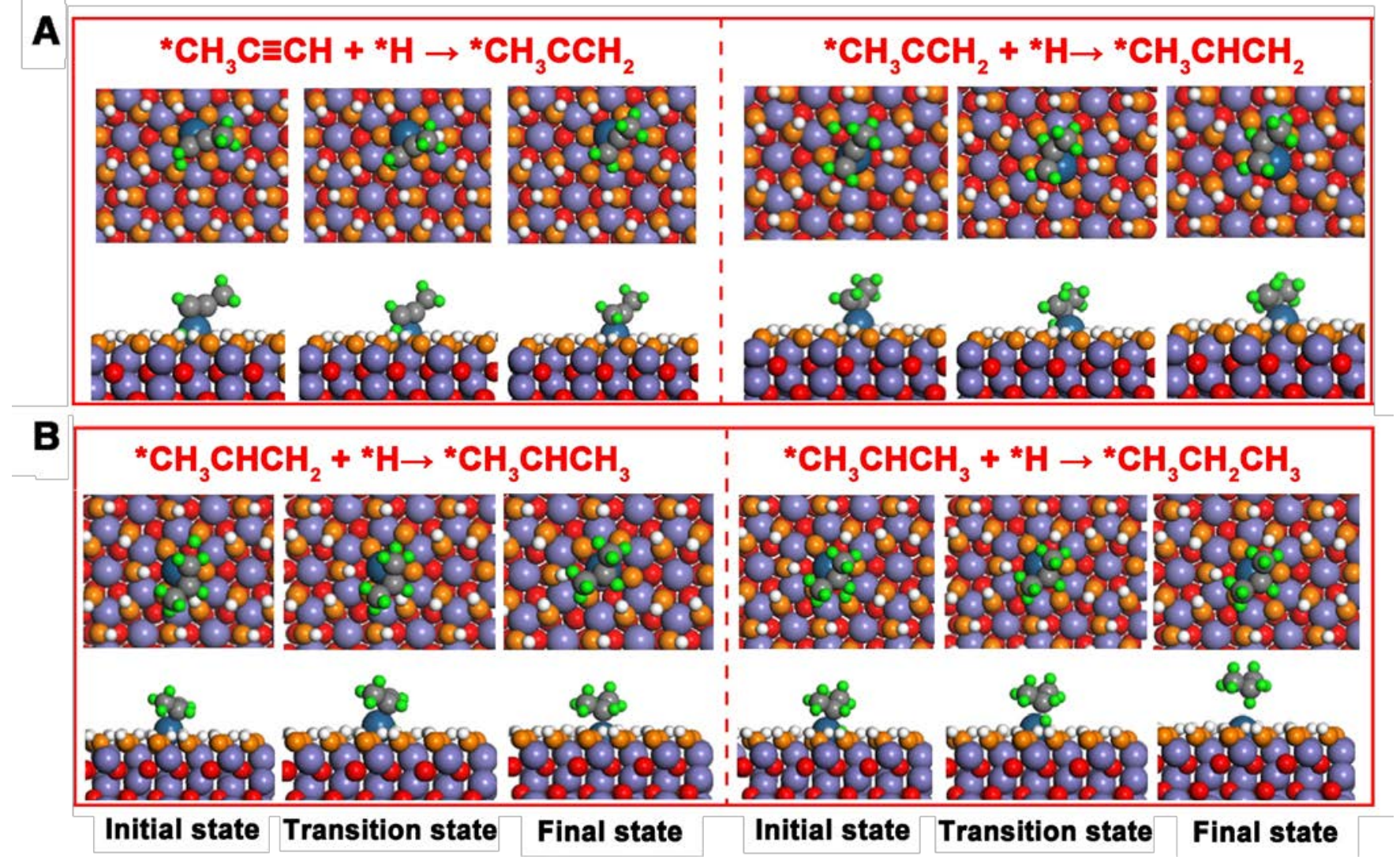

Figure S15. The corresponding atomic structures of different states in $\mathrm{C}-1$ path on $\mathrm{Pt} / \mathrm{Fe}_{2} \mathrm{O}_{3}(001)$ surface with 7-coordinated Pt single atom. (A) Top view (top) and side view (bottom) of different states during propyne hydrogenation to propylene, (B) Top view (top) and side view (bottom) of different states during propylene hydrogenation to propane. Considering the catalyst was exposed to $\mathrm{H}_{2}$ during reaction, $\mathrm{H}$ atoms may adsorb on $\mathrm{Fe}_{2} \mathrm{O}_{3}(001)$ surface. The surface $\mathrm{O}$ atoms, bulk $\mathrm{O}$ atoms, $\mathrm{Fe}$ atoms, Pt atoms, $\mathrm{H}$ atoms in molecules and other surface $\mathrm{H}$ atoms are represented with orange, red, purple, blue, green and white circles, respectively. 

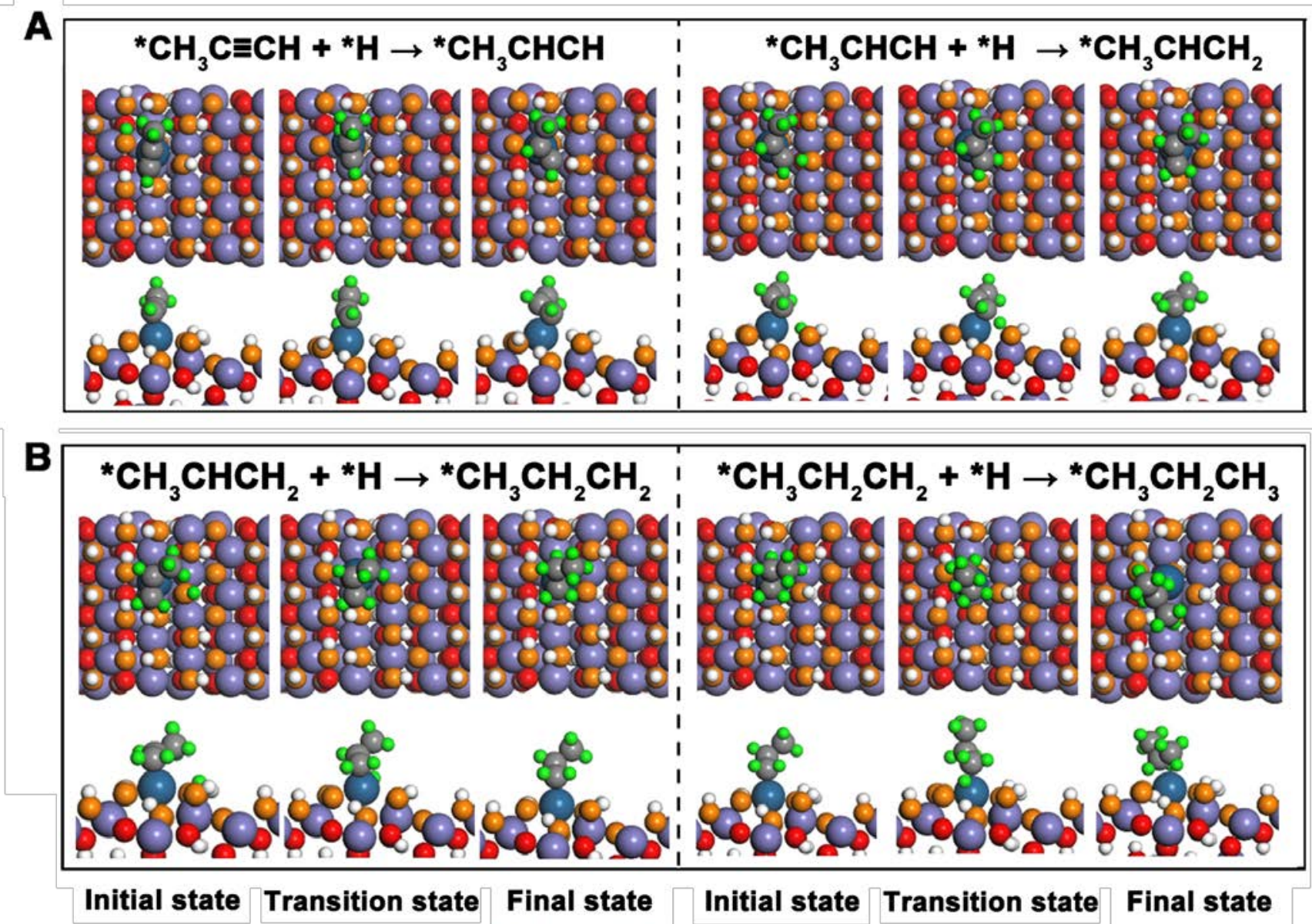

Figure S16. The corresponding atomic structures of different states in $\mathrm{C}-2$ path on $\mathrm{Pt} / \mathrm{FeOOH}$ (110) surface. (A) Top view (top) and side view (bottom) of different states during propyne hydrogenation to propylene, (B) Top view (top) and side view (bottom) of different states during propylene hydrogenation to propane. Considering the catalyst was exposed to $\mathrm{H}_{2}$ during reaction, $\mathrm{H}$ atoms may adsorb on $\mathrm{FeOOH}(110)$ surface. The two $\mathrm{O}$ atoms at top layer, other $\mathrm{O}$ atoms, Fe atoms, $\mathrm{Pt}$ atoms, $\mathrm{H}$ atoms in molecules and other surface $\mathrm{H}$ atoms are represented with orange, red, purple, blue, green and white circles, respectively. 

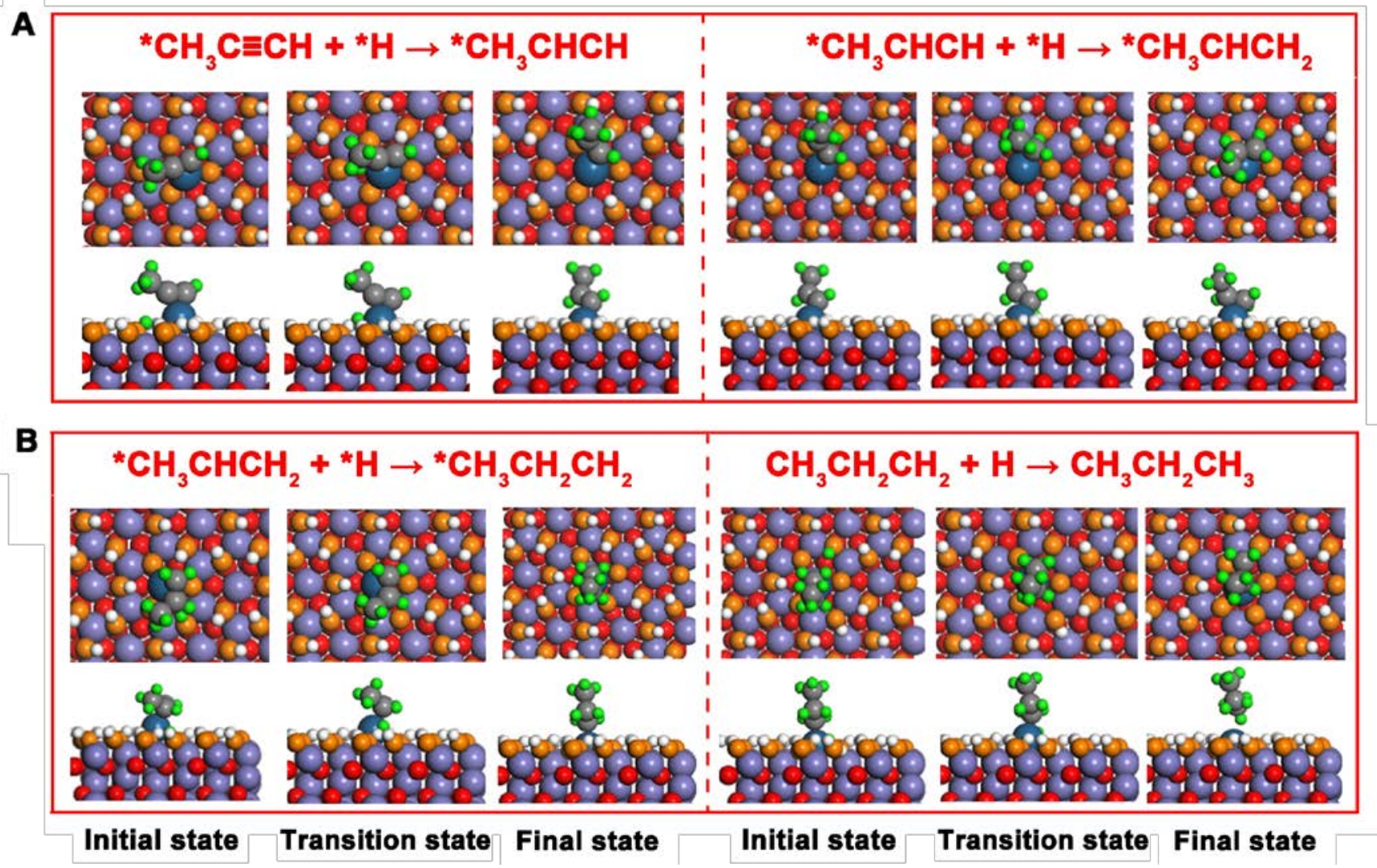

Figure S17. The corresponding atomic structures of different states in $\mathrm{C}-2$ path on $\mathrm{Pt} / \mathrm{Fe}_{2} \mathrm{O}_{3}(001)$ surface with 7-coordinated Pt single atom. (A) Top view (top) and side view (bottom) of different states during propyne hydrogenation to propylene, (B) Top view (top) and side view (bottom) of different states during propylene hydrogenation to propane. Considering the catalyst was exposed to $\mathrm{H}_{2}$ during reaction, $\mathrm{H}$ atoms may adsorb on $\mathrm{Fe}_{2} \mathrm{O}_{3}(001)$ surface. The surface $\mathrm{O}$ atoms, bulk $\mathrm{O}$ atoms, $\mathrm{Fe}$ atoms, Pt atoms, $\mathrm{H}$ atoms in molecules and other surface $\mathrm{H}$ atoms are represented with orange, red, purple, blue, green and white circles, respectively. 

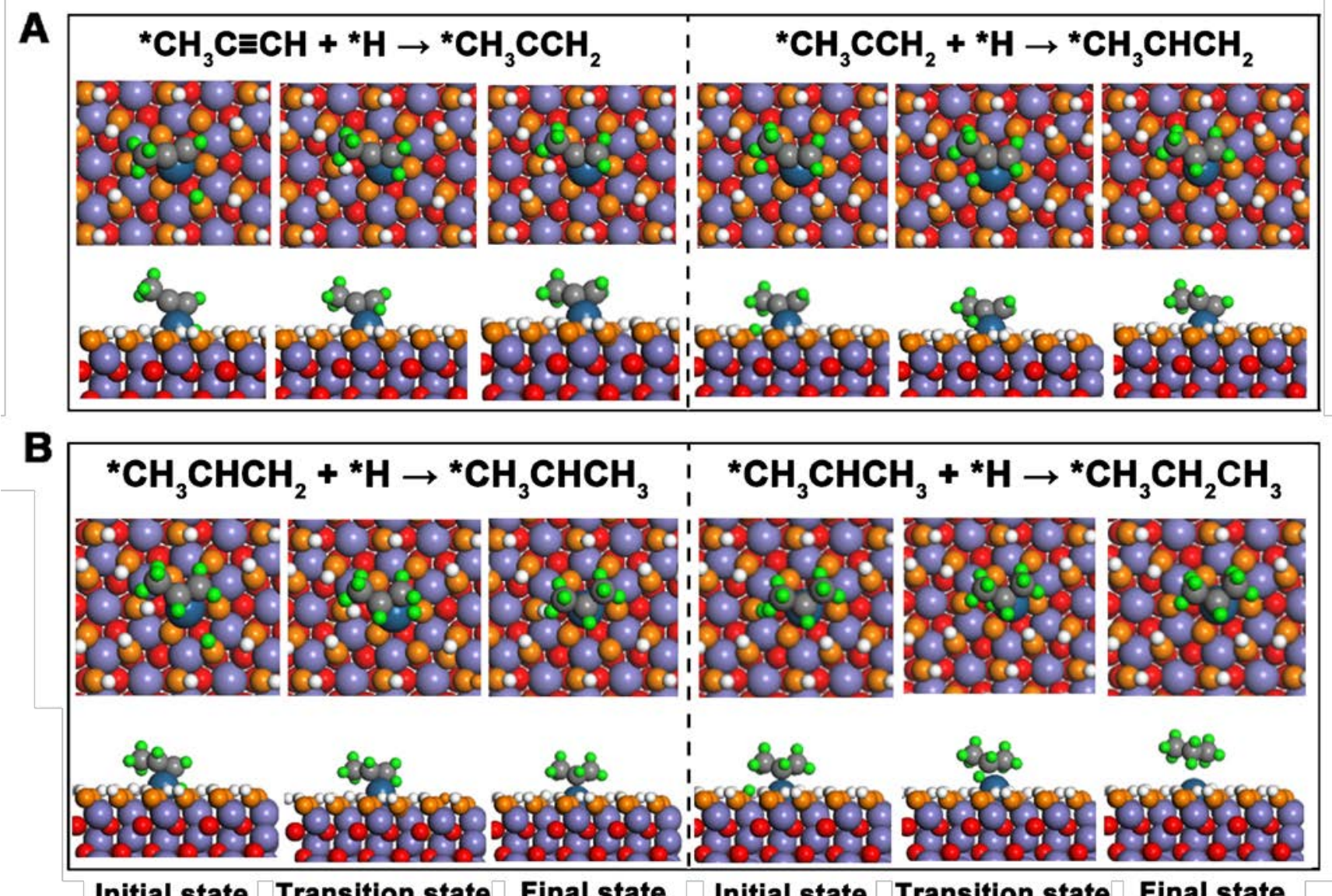

Figure S18. The corresponding atomic structures of different states in $\mathrm{C}-1$ path on $\mathrm{Pt} / \mathrm{Fe}_{2} \mathrm{O}_{3}(001)$ surface with 4-coordinated Pt single atom. (A) Top view (top) and side view (bottom) of different states during propyne hydrogenation to propylene, (B) Top view (top) and side view (bottom) of different states during propylene hydrogenation to propane. Considering the catalyst was exposed to $\mathrm{H}_{2}$ during reaction, $\mathrm{H}$ atoms may adsorb on $\mathrm{Fe}_{2} \mathrm{O}_{3}(001)$ surface. The surface $\mathrm{O}$ atoms, bulk $\mathrm{O}$ atoms, $\mathrm{Fe}$ atoms, Pt atoms, $\mathrm{H}$ atoms in molecules and other surface $\mathrm{H}$ atoms are represented with orange, red, purple, blue, green and white circles, respectively. 


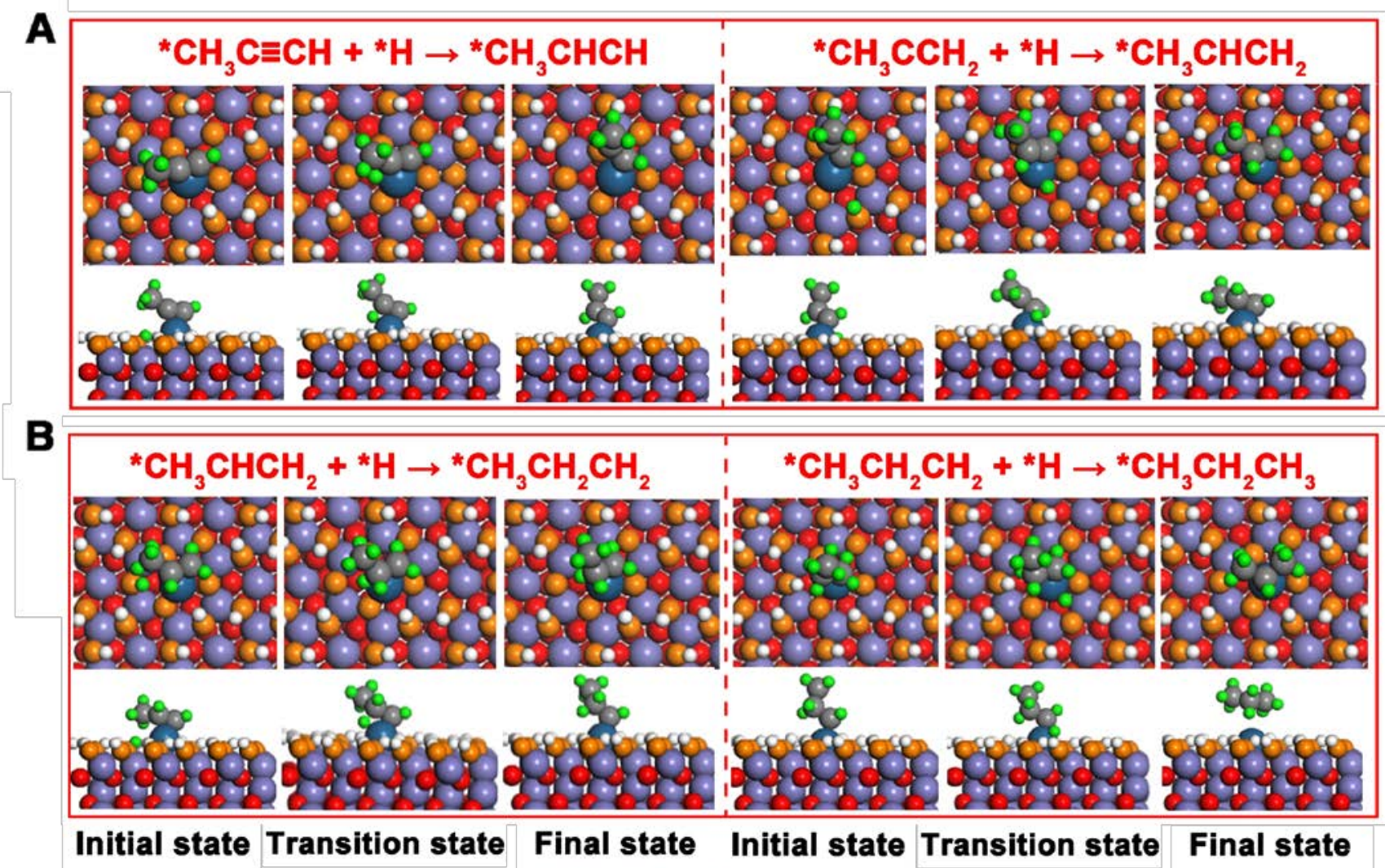

Figure S19. The corresponding atomic structures of different states in $\mathrm{C}-2$ path on $\mathrm{Pt} / \mathrm{Fe}_{2} \mathrm{O}_{3}(001)$ surface with 4-coordinated Pt single atom. (A) Top view (top) and side view (bottom) of different states during propyne hydrogenation to propylene, (B) Top view (top) and side view (bottom) of different states during propylene hydrogenation to propane. Considering the catalyst was exposed to $\mathrm{H}_{2}$ during reaction, $\mathrm{H}$ atoms may adsorb on $\mathrm{Fe}_{2} \mathrm{O}_{3}(001)$ surface. The surface $\mathrm{O}$ atoms, bulk $\mathrm{O}$ atoms, $\mathrm{Fe}$ atoms, Pt atoms, $\mathrm{H}$ atoms in molecules and other surface $\mathrm{H}$ atoms are represented with orange, red, purple, blue, green and white circles, respectively. 
Table S1. Summary of XPS results for the fresh catalysts

\begin{tabular}{|c|c|c|c|c|c|c|c|c|c|}
\hline \multirow{2}{*}{ Sample } & \multicolumn{4}{|c|}{ BEs of FeOOH (eV) } & \multicolumn{3}{|c|}{ BEs of $\mathrm{Fe}_{2} \mathrm{O}_{3}(\mathrm{eV})$} & \multirow{2}{*}{$\begin{array}{l}\mathrm{H}-\mathrm{O}-\mathrm{H} \\
\mathrm{O}_{4} 1 \mathrm{~s}^{d}\end{array}$} & \multirow{2}{*}{$\begin{array}{c}\mathrm{FeOOH} / \mathrm{Fe}_{2} \mathrm{O}_{3}{ }^{e} \\
(\%)\end{array}$} \\
\hline & Fe $2 p_{3 / 2}$ & Fe $2 \mathrm{p}_{1 / 2}$ & $\mathrm{O}_{1} 1 \mathrm{~s}^{a}$ & $\mathrm{O}_{2} 1 \mathrm{~s}^{b}$ & $\mathrm{Fe} 2 \mathrm{p}_{3 / 2}$ & $\mathrm{Fe} 2 \mathrm{p}_{1 / 2}$ & $\mathrm{O}_{3} 1 \mathrm{~s}^{c}$ & & \\
\hline $\mathrm{FeOOH}$ & 712.3 & 725.1 & 529.5 & 531.4 & - & - & - & 532.6 & $100 / 0$ \\
\hline S-1 & 712.3 & 725.1 & 529.5 & 531.4 & 710.7 & 723.8 & 530.2 & 532.6 & $90.9 / 9.1$ \\
\hline S-2 & 712.3 & 725.1 & 529.5 & 531.4 & 710.7 & 723.8 & 530.2 & 532.6 & $85.5 / 14.5$ \\
\hline S-3 & 712.3 & 725.1 & 529.5 & 531.4 & 710.7 & 723.8 & 530.2 & 532.6 & $73.8 / 26.2$ \\
\hline $\mathrm{S}-4$ & 712.3 & 725.1 & 529.5 & 531.4 & 710.7 & 723.8 & 530.2 & 532.6 & $91.3 / 8.7$ \\
\hline $\mathrm{Fe}_{2} \mathrm{O}_{3}$ & - & - & - & - & 710.7 & 723.8 & 530.2 & 532.6 & $0 / 100$ \\
\hline \multicolumn{10}{|c|}{${ }^{a}: \mathrm{O}_{1}$ represents the $\mathrm{O}$ connected with $\mathrm{Fe}$ in $\mathrm{FeOOH}$; } \\
\hline \multicolumn{10}{|c|}{${ }^{b}: \mathrm{O}_{2}$ represents the $\mathrm{O}$ connected with $\mathrm{H}$ in $\mathrm{FeOOH}$; } \\
\hline \multicolumn{10}{|c|}{$c: \mathrm{O}_{3}$ represents the $\mathrm{O}$ in $\mathrm{Fe}_{2} \mathrm{O}_{3}$} \\
\hline d: $\mathrm{O}_{4}$ repr & nts the & in $\mathrm{H}_{2} \mathrm{C}$ & & & & & & & \\
\hline
\end{tabular}


Table S2. Physicochemical properties different samples

\begin{tabular}{cccccc}
\hline Sample & Calcination T $\left({ }^{\circ} \mathrm{C}\right)$ & Pt content $^{a}(\mathrm{wt} . \%)$ & $\mathrm{PD}^{b}(\mathrm{~nm})$ & $\mathrm{PV}^{b}\left(\mathrm{~cm}^{3} / \mathrm{g}\right)$ & $\mathrm{SA}^{b}\left(\mathrm{~m}^{2} / \mathrm{g}\right)$ \\
\hline FeOOH & - & - & 1.81 & 0.09 & 27.32 \\
S-1 & 150 & 0.094 & 3.64 & 0.21 & 115.40 \\
S-2 & 200 & 0.101 & 3.48 & 0.24 & 129.55 \\
S-3 & 300 & 0.109 & 3.91 & 0.24 & 151.59 \\
S-4 & 400 & 0.114 & 4.05 & 0.20 & 181.62 \\
$0.5 \%$ Pt-FeO & 400 & 0.522 & 3.87 & 0.21 & 168.20 \\
$1 \%$ Pt-FeO $_{x}$ & 400 & 1.093 & 3.81 & 0.20 & 160.12 \\
\hline
\end{tabular}

${ }^{a}$ : Pt content was deterimend by ICP-OES.

${ }^{b}$ : PD, PV and SA represent pore diameter, pore volume, and surface area, respectively. 
Table S3. Summary of EXFAS fitting.

\begin{tabular}{cccccc}
\hline Sample & Scatter path & $\mathrm{CN}$ & $\mathrm{R}(\AA)$ & $\sigma 2\left(10^{-3} \AA^{2}\right)$ & $\Delta \mathrm{Eo}(\mathrm{eV})$ \\
\hline $\mathrm{S}-1$ & $\mathrm{Pt}-\mathrm{O}$ & $3.43 \pm 0.85$ & $2.04 \pm 0.002$ & $2.52 \pm 2.99$ & $6.79 \pm 3.02$ \\
$\mathrm{~S}-2$ & $\mathrm{Pt}-\mathrm{O}$ & $4.35 \pm 0.97$ & $2.05 \pm 0.01$ & $5.87 \pm 3.67$ & $14.31 \pm 2.42$ \\
$\mathrm{~S}-3$ & $\mathrm{Pt}-\mathrm{O}$ & $4.75 \pm 0.81$ & $2.00 \pm 0.04$ & $3.09 \pm 1.83$ & $9.77 \pm 1.98$ \\
$\mathrm{~S}-4$ & $\mathrm{Pt}-\mathrm{O}$ & $5.04 \pm 0.73$ & $2.01 \pm 0.03$ & $3.14 \pm 1.82$ & $10.86 \pm 1.98$ \\
$\mathrm{Pt} \mathrm{foil}$ & $\mathrm{Pt}-\mathrm{Pt}$ & 12 & $2.76 \pm 0.003$ & $4.29 \pm 0.45$ & $7.46 \pm 0.47$ \\
$\mathrm{PtO}_{2}$ & $\mathrm{Pt}-\mathrm{O}$ & 6 & $2.02 \pm 0.011$ & $1.65 \pm 1.22$ & $11.58 \pm 1.86$ \\
\hline
\end{tabular}


Table S4. Summary of XPS results for the spent catalysts

\begin{tabular}{|c|c|c|c|c|c|c|c|c|c|}
\hline \multirow{2}{*}{ Sample } & \multicolumn{4}{|c|}{ BEs of FeOOH $(\mathrm{eV})$} & \multicolumn{3}{|c|}{ BEs of $\mathrm{Fe}_{2} \mathrm{O}_{3}(\mathrm{eV})$} & \multirow{2}{*}{$\begin{array}{c}\mathrm{H}-\mathrm{O}-\mathrm{H} \\
\mathrm{O}_{4} 1 \mathrm{~s}^{d}\end{array}$} & \multirow{2}{*}{$\begin{array}{c}\mathrm{FeOOH} / \mathrm{Fe}_{2} \mathrm{O}_{3} \mathrm{e} \\
(\%)\end{array}$} \\
\hline & Fe $2 p_{3 / 2}$ & $\mathrm{Fe} 2 \mathrm{p}_{1 / 2}$ & $\mathrm{O}_{1} 1 \mathrm{~s}^{a}$ & $\mathrm{O}_{2} 1 \mathrm{~s}^{b}$ & $\mathrm{Fe} 2 \mathrm{p}_{3 / 2}$ & Fe $2 p_{1 / 2}$ & $\mathrm{O}_{3} 1 \mathrm{~s}^{c}$ & & \\
\hline S-1 & 712.3 & 725.1 & 529.5 & 531.4 & 710.7 & 723.8 & 530.2 & 532.5 & $90.8 / 9.2$ \\
\hline S-2 & 712.2 & 725.0 & 529.5 & 531.4 & 710.6 & 723.7 & 530.2 & 532.6 & $85.3 / 14.7$ \\
\hline S-3 & 712.2 & 725.0 & 529.5 & 531.4 & 710.7 & 723.7 & 530.2 & 532.5 & $73.4 / 26.6$ \\
\hline S-4 & 712.3 & 725.2 & 529.4 & 531.3 & 710.8 & 723.9 & 530.2 & 532.5 & $91.4 / 8.6$ \\
\hline
\end{tabular}

${ }^{a}: \mathrm{O}_{1}$ represents the $\mathrm{O}$ connected with $\mathrm{Fe}$ in $\mathrm{FeOOH}$;

b: $\mathrm{O}_{2}$ represents the $\mathrm{O}$ connected with $\mathrm{H}$ in $\mathrm{FeOOH}$;

c: $\mathrm{O}_{3}$ represents the $\mathrm{O}$ in $\mathrm{Fe}_{2} \mathrm{O}_{3}$;

d: $\mathrm{O}_{4}$ represents the $\mathrm{O}$ in $\mathrm{H}_{2} \mathrm{O}$;

$e^{e}: \mathrm{FeOOH} / \mathrm{Fe}_{2} \mathrm{O}_{3}$ was calculated by Fe 2p XPS spectra. 


\section{References}

(1) Wang, B.; Wu, H.; Yu, L.; Xu, R.; Lim, T.; Lou, X. Template-free formation of uniform urchin-like $\alpha$-FeOOH hollow spheres with superior capability for water treatment. Adv. Mater. 2012, 24, 1111-1116.

(2) Kresse, G.; Furthmüller, J. Efficiency of ab-initio total energy calculations for metals and semiconductors using a plane-wave basis set. Comput. Mater. Sci. 1996, 6, 15-50.

(3) Blöchl, P. Projector augmented-wave method. Phys. Rev. B. 1994, 50, 17953-17979.

(4) Perdew, J.; Burke, K.; Ernzerhof, M. Generalized gradient approximation made simple. Phys. Rev. Lett. 1996, 77, 3865-3868.

(5) Hensley, A.; Hong, Y.; Zhang, R.; Zhang, H.; Sun, J.; Wang, Y.; McEwen, J. Enhanced $\mathrm{Fe}_{2} \mathrm{O}_{3}$ reducibility via surface modification with $\mathrm{Pd}$ : characterizing the synergy within $\mathrm{Pd} / \mathrm{Fe}$ catalysts for hydrodeoxygenation reactions. ACS Catal. 2014, 4, 3381-3392.

(6) Alexandrov, V.; Rosso, K. Ab initio modeling of Fe (II) adsorption and interfacial electron transfer at goethite $(\alpha-\mathrm{FeOOH})$ surfaces. Phys. Chem. Chem. Phys. 2015, 17, 14518-14531.

(7) Grimme, S.; Antony, J.; Ehrlich, S.; Krieg, H. A consistent and accurate ab initio parametrization of density functional dispersion correction (DFT-D) for the 94 elements H-Pu. J. Chem. Phys. 2010, 132, 154104.

(8) Henkelman, G.; Uberuaga, B.; Jónsson, H. Climbing image nudged elastic band method for finding saddle points and minimum energy paths. J. Chem. Phys. 2000, 113, 9901-9904.

(9) Henkelman, G.; Jónsson, H. A dimer method for finding saddle points on high dimensional potential surfaces using only first derivatives. J. Chem. Phys. 1999, 111, 7010-7022.

(10) Kaestner, J.; Sherwood, P. Superlinearly converging dimer method for transition state search. J. Chem. Phys. 2008, 128, 014106-014111 
(11) Li, Y., Ho, W., Lv, K., Zhu, B. and Lee, S. C. Carbon vacancy-induced enhancement of the visible light-driven photocatalytic oxidation of $\mathrm{NO}$ over $\mathrm{g}-\mathrm{C}_{3} \mathrm{~N}_{4}$ nanosheets. Appl. Surf. Sci. 2017, 430, 380-389.

(12) Zhang, Z., Zhang, Y., Lu, L., Si, Y., Zhang, S., Cheng, Y., Dai, K., Duan, P., Duan, L., Liu, J. Graphitic carbon nitride nanosheet for photocatalytic hydrogen production: the impact of morphology and element composition. Appl. Surf. Sci. 2017, 391, 369-375. 